\title{
DNA-only bioassay for simultaneous detection of proteins and nucleic acids
}

\author{
Aida Montserrat Pagès ${ }^{1} \cdot$ Saba Safdar ${ }^{1} \cdot$ Karen Ven $^{1} \cdot$ Jeroen Lammertyn ${ }^{1} \cdot$ Dragana Spasic $^{1}$
}

Received: 20 April 2021 / Revised: 26 May 2021 / Accepted: 7 June 2021 / Published online: 28 June 2021

(C) Springer-Verlag GmbH Germany, part of Springer Nature 2021

\begin{abstract}
Testing multiple biomarkers, as opposed to one, has become a preferred approach for diagnosing many heterogeneous diseases, such as cancer and infectious diseases. However, numerous technologies, including gold standard ELISA and PCR, can detect only one type of biomarker, either protein or nucleic acid (NA), respectively. In this work, we report for the first time simultaneous detection of proteins and NAs in the same solution, using solely functional NA (FNA) molecules. In particular, we combined the thrombin binding aptamer (TBA) and the 10-23 RNA-cleaving DNA enzyme (DNAzyme) in a single aptazyme molecule (Aptazyme ${ }_{1.15-3^{\prime}}$ ), followed by extensive optimization of buffer composition, sequences and component ratios, to establish a competitive bioassay. Subsequently, to establish a multiplex bioassay, we designed a new aptazyme (Aptazyme $2.20-5^{\prime}$ ) by replacing the target recognition and substrate sequences within Aptazyme ${ }_{1.15-3^{\prime}}$. This designing process included an in silico study, revealing the impact of the target recognition sequence on the aptazyme secondary structure and its catalytic activity. After proving the functionality of the new aptazyme in a singleplex bioassay, we demonstrated the capability of the two aptazymes to simultaneously detect thrombin and NA target, or two NA targets in a multiplex bioassay. High specificity in target detection was achieved with the limits of detection in the low nanomolar range, comparable to the singleplex bioassays. The presented results deepen the barely explored features of FNA for diagnosing multiple targets of different origins, adding an extra functionality to their catalogue.
\end{abstract}

Keywords DNAzyme $\cdot$ Aptazyme $\cdot$ Competitive bioassay $\cdot$ Multiplexing $\cdot$ Simultaneous detection

\section{Introduction}

The best therapeutic strategy for all diseases is an early and accurate diagnosis $[1,2]$, which, however, relies on the availability of biomarkers. Discovering a unique one for each disease can be fairly complex, especially when working with heterogeneous diseases, such as infectious diseases or cancer. To further advance their diagnosis, simultaneous evaluation of a panel of biomarkers, including both proteins and nucleic acids (NAs), has been shown as a promising strategy [2,3]. For example, it has been proven that integrating the host response factors can significantly improve the diagnosis of infectious diseases [4]. Moreover, targeting multiple regions of a viral genome provides specific information about the type of

Jeroen Lammertyn

jeroen.lammertyn@kuleuven.be

1 Department of Biosystems, Biosensors Group, KU Leuven University of Leuven, Willem de Croylaan 42,

3001 Leuven, Belgium virus next to circumventing problems with high viral mutation rates $[1,5]$. All these aspects are essential to successfully control infections during outbreaks, as we are currently witnessing during the COVID-19 pandemic. Also, it has been demonstrated that the detection of colorectal cancer by the widely used carcinoembryonic antigen reaches $30-40 \%$ of sensitivity, which remarkably increases to $88 \%$ when combined with the detection of free circulating DNA [6]. Moreover, the combination of biomarkers can also provide information about the stage of cancer as well as about the response to a therapy [7]. According to a recent review, one of the next goals in the detection of cancer biomarkers is to develop NA-based techniques for personalized and point-ofcare (POC) diagnostics that can detect both NA and non-NA targets [8]. This, however, poses a considerable challenge as multiple read-out platforms are still needed to accomplish this, which significantly complexifies diagnosis. For instance, despite being of high value as the gold standards, neither ELISA nor PCR can detect other types of targets but solely proteins or NAs, respectively. 
Functional nucleic acids (FNA) are a group of DNA and RNA molecules, holding functionalities beyond the storage and transfer of genetic information [9]. Among numerous FNA types, the two exploited in this work are aptamers, capable of specifically binding to a target, and DNA enzymes (DNAzymes), capable of catalyzing a reaction. Both FNAs have become increasingly popular over the years, thanks to the sizeable possibilities for their design and modifications [10]. Aptamers are single-stranded (ss) DNA or RNA molecules, which are selected from a substantial pool of random sequences through an in vitro iterative process, known as SELEX (systematic evolution of ligands by exponential enrichment), leading to the enrichment of those sequences showing the highest affinity for the target [11]. The use of aptamers as recognition elements offers several advantages over their protein analogues, such as high synthesis reproducibility and high stability in a wide range of conditions [12]. Moreover, the ease of labeling DNA sequences with functional molecules, or their immobilization on a surface makes aptamers suitable to developing bioassays in combination with different types of read-outs, such as optical, electrochemical, or mass-sensitive [13]. Similar to aptamers, DNAzymes are also selected through an in vitro iterative procedure for their capability of performing catalytic activities [14]. They can catalyze many different reactions, such as redox [15], phosphorylation [16], ligation [17], or RNA-cleavage [18], the latter forming the base of this work. RNAcleaving DNAzymes are composed of a catalytic core and two substrate-binding arms, responsible for enzymatic activity and target recognition, respectively. Similar to protein enzymes, their catalytic activity is dependent on specific cofactors, namely metal ions [19]. The option to integrate DNAzymes with several read-out methods expands their range of applications as well [20]. Interestingly, aptamers and DNAzymes have been also merged into a single molecule, known as aptazyme [21], which has unlocked a myriad of opportunities for applications in biosensing [22]. In this context, approaches using the properties of DNA beyond base-pairing have been studied, including aptamers for target recognition and DNAzymes for signal generation [23-25]. Although these approaches made an important contribution by demonstrating the potential of FNAs, to the best of our knowledge, they have never been used for multiplex detection of different types of targets in the same bioassay.

In this context, here we present an aptazyme-based DNA-only competitive bioassay capable of detecting both protein and NA targets or two different NA targets in the same reaction (Fig. 1). To accomplish this, we design two different aptazymes: (1) Aptazyme ${ }_{1.15-3}$ ', for detecting a protein target as well as an $\mathrm{NA}_{1}$ target, and (2) Aptazyme 2.20-5, for detecting an $\mathrm{NA}_{2}$ target.
Aptazyme $_{1.15-3}$, is constructed by combining a thrombin binding aptamer (TBA) as the target recognition element and a recently reported redesigned version of 10-23 core RNA-cleaving DNAzyme [26] for signal generation, referred to here as DNAzyme ${ }_{1}$. TBA has been selected as an attractive model system due to its extensive characterization and applicability in numerous bioassays [27]. The DNAzyme $_{1}$ was recently made in our group for optimal catalysis at the standard room temperature (RT, i.e., 20 $25^{\circ} \mathrm{C}$ ) [26], starting from the traditional DNAzyme that cleaves at elevated temperatures (ranging between 37 and $\left.55^{\circ} \mathrm{C}\right)[28,29]$. Aptazyme $2.20-5^{\prime}$ is designed by joining a random $\mathrm{NA}_{2}$ target recognition sequence with DNAzyme ${ }_{2}$. In the latter, the substrate binding arms of DNAzyme ${ }_{1}$ are modified to allow binding of a different substrate, thus enabling multiplexing. In both cases, to prevent the enzymatic activity of the DNAzyme in the absence of a target, the aptazyme is blocked with a complementary inhibitory sequence, which hinders the binding and the cleavage of the DNAzyme substrate. Adding thrombin or $\mathrm{NA}_{1}$ target to the solution competitively removes the inhibitory sequence, allowing the substrate to bind. Subsequently, the DNAzyme can cleave the RNA bases in the substrate, resulting in its dissociation. Since the substrate sequence is labelled with a fluorophore (FAM or HEX, respectively referred to as $\mathrm{F}$ and $\mathrm{H}$ ) on one end and a quencher (Iowa Black ${ }^{\circledR}$ FQ referred to as Q) on the other, the distance increases between them upon the cleavage, resulting in a fluorescence signal increase. Because one aptazyme can catalyze the cleavage of multiple substrates, this approach provides an amplification of the signal.

To establish such a competitive (multiplex) bioassay, in this paper we first optimize conditions permitting uncompromised functionality of both aptazyme elements (i.e., target recognition part and DNAzyme) in the same buffer. Next, different aspects of the competitive bioassay are scrutinized, including the concentrations of the different reaction elements and the incubation times to inhibit aptazyme activity. Finally, the specificity and sensitivity of the multiplexed bioassays are evaluated. As such, we report here the first ever study on using aptazymes for multiplex detection of different types of targets in the same bioassay, which offers massive advantage for implementing such bioassays on POC platforms and/or when having limited patients' sample volume (both highly relevant for instance in the context of infectious diseases diagnostics). Although demonstrated using simple model systems, the flexibility and ease of designing NA receptors demonstrate the huge potential of this approach to be implemented for a variety of different targets and is aligned with the expectations in the field to establish NA-based techniques for detecting both NA and non-NA targets. 


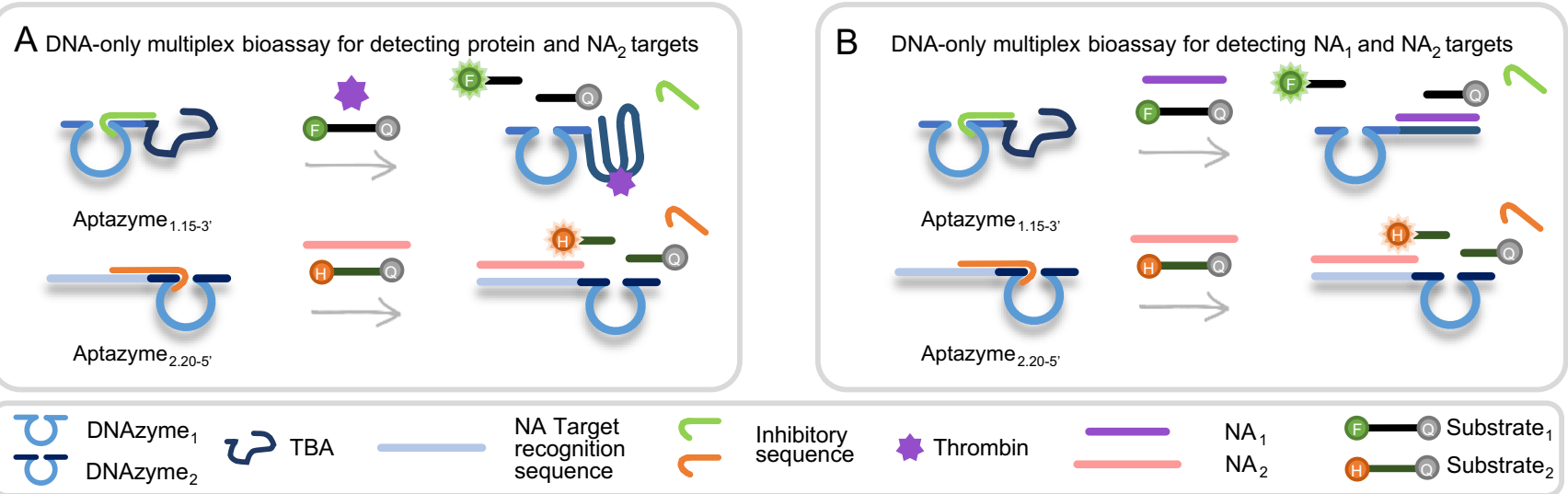

Fig. 1 Schematic illustration of the proposed competitive bioassay for the simultaneous detection of $\mathbf{A}$ protein and $\mathrm{NA}_{2}$ target, and $\mathbf{B}$ two NA targets together $\left(\mathrm{NA}_{1}\right.$ and $\left.\mathrm{NA}_{2}\right)$. The detection of a $\mathrm{NA}_{1}$ target by Aptazyme $_{1.15-3^{\prime}}$, was simply achieved by using the complementary sequence of TBA as the target. DNAzyme ${ }_{1}$ is always part of Aptazyme $_{1.15-3}$ ' and correspondingly cleaves Substrate ${ }_{1}$, whereas DNAzyme $_{2}$ is part of Aptazyme ${ }_{2.20-5^{\prime} \text {, thereby cleaving Substrate }}$. TBA stands for thrombin binding aptamer

\section{Materials and methods}

\section{Reagents and buffers}

The oligonucleotides presented in this paper were purchased from Integrated DNA Technologies (IDT, Leuven, Belgium) and used without further purification. All the sequences are summarized in Table $\mathrm{S} 1$ in Supplementary Information (ESM). Potassium chloride $(\mathrm{KCl})$ and ethylenediaminetetraacetic acid (EDTA) were purchased from Acros Organics (Geel, Belgium). Trisethylenediaminetetraacetic acid (TE, 100×), and glycine were obtained from Sigma-Aldrich (St. Louis, USA). Magnesium chloride solution $\left(\mathrm{MgCl}_{2}\right)$ was acquired from Fisher Scientific (Leicestershire, England) and Tris- $\mathrm{HCl}$ $(\mathrm{pH}$ 8.8) was obtained from Genetex Inc. (Irvine, USA). Human $\alpha$-thrombin was purchased from Haematologic Technologies (Essex Junction, USA). TE was diluted $100 \times$ and used as a buffer solution for the preparation of intermediate solutions of the DNA sequences. The $\mathrm{pH}$ of the buffers was adjusted using hydrochloric acid $(\mathrm{HCl})$ from Sigma-Aldrich (St. Louis, USA). All dilutions were prepared using UltraPure distilled water (DNAse-RNAse free, Invitrogen, Carlsbad, USA) unless stated otherwise. All reaction mixes were prepared in DNA or Protein LoBind tubes (Eppendorf, Hamburg, Germany) and the fluorescence was measured in 384-well black-clear bottom microplates (Glasatelier Saillart, Meerhout, Belgium) using the SpectraMax ID3 microplate reader (Molecular Devices LLC, San Jose, USA). The composition of all the buffers used in this paper is summarized in Table 1. All the concentrations of different bioassay components refer to the concentration in the final volume, unless stated otherwise.

\section{Development of the competitive assay}

\section{Buffer screening}

The thrombin binding of the two aptamers used (i.e., $\mathrm{TBA}_{15}$ and $\mathrm{TBA}_{28}$, where 15 and 28 correspond to their respective lengths in nucleotides (nts) and are represented as sequences nr 1 and 2 respectively in Table S1, ESM) was evaluated in four different buffers: Buffer ${ }_{\text {DNAzyme }}$, Buffer ${ }_{A}, B$ Buffer $_{B}$, and Buffer $_{C}$ (for composition, see Table 1). This was done using the fiber optic surface plasmon resonance (FO-SPR) biosensor from FOx Biosystems (Diepenbeek, Belgium) (Fig. S1, ESM). The FO-SPR probes were manufactured and functionalized as described in Daems et al. [30]. Briefly, FO-SPR probes, sputtered with a gold layer, were functionalized with the aptamer $\mathrm{TBA}_{15}$ or $\mathrm{TBA}_{28}$ through thiol binding (Fig. S2, ESM). Subsequently, the functionalized FO-SPR probes were immersed in $150 \mu \mathrm{L}$ of the four different buffers containing a range of thrombin concentrations $(0,62,124$, and $248 \mathrm{nM})$. The resonance wavelength was measured for $20 \mathrm{~min}$ at RT and the shift in the resonance wavelength was calculated per tested concentration.

In parallel, the cleavage activity of the DNAzyme ${ }_{1}(\mathrm{nr} 3$ in Table S1, ESM), used for establishing the competitive bioassay, was tested in $25 \mu \mathrm{L}$ of the four buffers (Buffer DNAzyme, Buffer $_{\mathrm{A}}$, Buffer $_{\mathrm{B}}$, and Buffer $_{\mathrm{C}}$ ) containing $250 \mathrm{nM}$ of DNAzyme $_{1}$ and $250 \mathrm{nM}$ of Substrate ${ }_{1}$, the latter dually labelled with $\mathrm{F}$ on the $5^{\prime}$ end and $\mathrm{Q}$ on the $3^{\prime}$ end (nr 5 in Table S1, ESM). The activity of DNAzyme ${ }_{1}$ in this and all subsequent experiments with Aptazyme ${ }_{1.15-3^{\prime}}$ was monitored on a microplate reader, by measuring the fluorescence signal for 10 min at RT using 485 and $535 \mathrm{~nm}$ as excitation and emission wavelengths, respectively, whereas all measurements were performed in triplicates. 
Table 1 Composition of the buffers used in this work

\begin{tabular}{ll}
\hline Name & Composition \\
\hline Buffer $_{\text {DNAzyme }}$ & $50 \mathrm{mM} \mathrm{KCl}$ and $20 \mathrm{mM} \mathrm{MgCl}_{2}$ in $10 \mathrm{mM}$ Tris-HCl, pH 8.3 \\
Buffer $_{\mathrm{A}}$ & $5 \mathrm{mM} \mathrm{KCl}$ and $1 \mathrm{mM} \mathrm{MgCl}_{2}$ in $20 \mathrm{mM}$ Tris-HCl, pH 8.3 (used in all the measurements, unless stated otherwise) \\
Buffer $_{\mathrm{B}}$ & $5 \mathrm{mM} \mathrm{KCl}, 1 \mathrm{mM} \mathrm{MgCl}$, and $0.1 \mathrm{mM}$ EDTA in $10 \mathrm{mM}$ Tris-HCl, pH 8.0 \\
Buffer $_{\mathrm{C}}$ & $5 \mathrm{mM} \mathrm{KCl}$ and $1 \mathrm{mM} \mathrm{MgCl}_{2}$ in $10 \mathrm{mM}$ Tris-HCl, pH 8.0
\end{tabular}

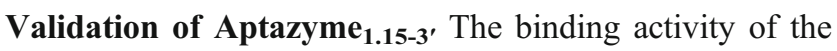
TBA $_{15}$ within the constructed aptazyme was evaluated in Buffer $_{\mathrm{A}}$ (selected as the most optimal based on buffer screening as described above) using the same FO-SPR technique. The FO-SPR probes, functionalized with Aptazyme 1.15-3'Thiol $^{\prime}$ through thiol binding ( $\mathrm{nr} 7$ in Table S1, ESM), were immersed in $150 \mu \mathrm{L}$ of Buffer $_{\mathrm{A}}$ containing different concentrations of thrombin $(0,62,124$, and $248 \mathrm{nM})$. The FO-SPR probes functionalized with $\mathrm{TBA}_{15}$ were used as a reference.

The cleavage activity of the DNAzyme ${ }_{1}$ within the Aptazyme $_{1.15-3^{\prime}}$ and Aptazyme ${ }_{1 . \text { PolyT }}$ (nr 8 and 9, respectively in Table S1, ESM) was tested in $25 \mu \mathrm{L}$ of Buffer $_{\mathrm{A}}$ containing $250 \mathrm{nM}$ of one of the respective aptazymes and $250 \mathrm{nM}$ of Substrate $_{1}$. The same reaction performed with DNAzyme served as a positive control.

Optimization of Aptazyme 1.15-3 , blocking The blocking of the Aptazyme ${ }_{1.15-3}$, activity was tested using two different inhibitory sequences (Inhibitor ${ }_{1 \mathrm{~A}}$ and Inhibitor $_{1 \mathrm{~B}}$ at 2500 $\mathrm{nM}$, nr 16 and 17, respectively in Table S1, ESM) at two different incubation times (15 and $30 \mathrm{~min}$ ). After selecting Inhibitor $_{1 \mathrm{~B}}$ and $15 \mathrm{~min}$ of reaction as the most optimal conditions, we next tested the potential of thrombin to un-

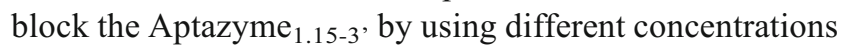
of Inhibitor $_{1 \mathrm{~B}}(250,500,1250$, and $2500 \mathrm{nM})$ and one thrombin concentration $(248 \mathrm{nM})$. In all these experiments, $250 \mathrm{nM}$ of Substrate $_{1}$ was added to generate fluorescence signal, and monitored for $10 \mathrm{~min}$ on a microplate reader as previously described. The signal generated upon the addition of thrombin was calculated by subtracting the signal in the absence of thrombin from the signal in its presence. All measurements were performed in $35 \mu \mathrm{L}$ with $250 \mathrm{nM}$ of Aptazyme $_{1.15-3}{ }^{\prime}$.

Competitive bioassay The possibility to detect either protein or NA target using the same approach was assessed by incubating $250 \mathrm{nM}$ of Aptazyme ${ }_{1.15-3}$, with $500 \mathrm{nM}$ of Inhibitor ${ }_{1 \mathrm{~B}}$ (1:2 ratio). Next, $0,15.5,31,62,124$, and $248 \mathrm{nM}$ of the target, being either thrombin or $\mathrm{NA}_{1}$ (nr 19 in Table S1, ESM), and $750 \mathrm{nM}$ of Substrate $_{1}$ were added, in a total volume of $35 \mu \mathrm{L}$. The optimization of the concentrations of the components in the competitive bioassays has been described in Optimization of Substrate1 concentration (ESM).

\section{Development of the multiplex bioassay}

Aptazyme $_{2}$ design For establishing the multiplex bioassay, DNAzyme $_{2}$, Aptazyme $2.28-3$, (nr 4 and 10, respectively in Table S1, ESM), and the variations of Aptazyme $2.28-3$, (nr 11-15 in Table S1, ESM) were designed. The secondary structures of newly designed aptazymes were studied using the OligoAnalyzer 3.1 tool of IDT Technologies (https://eu. idtdna.com/calc/analyzer). Their cleavage activity was tested in $25 \mu \mathrm{L}$ of Buffer $_{\mathrm{A}}$, containing one of these sequences at 250 $\mathrm{nM}$, together with $250 \mathrm{nM}$ of Substrate $_{2}$, which is dually labelled with $\mathrm{H}$ and $\mathrm{Q}$ on the 5' and 3' end, respectively (nr 6 in Table S1, ESM). The kinetic activity was monitored by measuring the fluorescence signal for $10 \mathrm{~min}$ at RT using 536 and $606 \mathrm{~nm}$ as excitation and emission wavelengths, respectively. All measurements involving multiplex bioassay were performed in triplicates.

Validation of the second competitive bioassay using Aptazyme 2.20-5' The second competitive bioassay was developed with Aptazyme $2.20-5$, selected as the best performing sequence, under the same conditions as described above: $250 \mathrm{nM}$ of Aptazyme $2.20-5$, was incubated together with Inhibitor $_{2}$ (nr 18 in Table S1, ESM) in a 1:2 ratio for $15 \mathrm{~min}$ at RT, followed by adding several concentrations of the $\mathrm{NA}_{2}$ target (nr 20 in Table S1, ESM) - 0, 15.5, 31, 62, 124, and

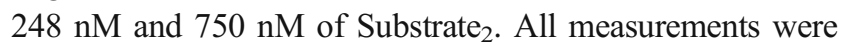
performed in a total volume of $35 \mu \mathrm{L}$.

Evaluation of competitive bioassay specificity in multiplex conditions The compatibility of the two substrates was tested in a volume of $35 \mu \mathrm{L}$ containing Substrate or Substrate $_{2}$, or both together, each at $250 \mathrm{nM}$ concentration. The fluorescent signal was measured for 10 min using 485-535 and 536-606 $\mathrm{nm}$ as excitation-emission wavelengths pair for the $\mathrm{F}$ and $\mathrm{H}$ fluorescent labels, respectively. Similarly, the specificity of the aptazymes for their substrate was evaluated by combining $250 \mathrm{nM}$ of each aptazyme with $250 \mathrm{nM}$ of each substrate, separately or in combination. Next, the specificity of the bioreceptors for their targets was evaluated in a solution of $35 \mu \mathrm{L}$ containing Aptazyme ${ }_{1.15-3}$, and Aptazyme $2.20-5$, (each at $125 \mathrm{nM}$ ), previously inhibited with $250 \mathrm{nM}$ of their respective inhibitors (thus keeping 1:2 ratio). Then, $248 \mathrm{nM}$ of one 
or both targets was added to the solution together with $375 \mathrm{nM}$ of Substrate $_{1}$ and $375 \mathrm{nM}$ of Substrate . $_{2}$.

Multiplex bioassay The performance of the multiplex bioassay was tested by combining, in a $35 \mu \mathrm{L}$ solution, $125 \mathrm{nM}$ of Aptazyme $_{1.15-3}$, inhibited with $250 \mathrm{nM}$ of Inhibitor ${ }_{1 \mathrm{~B}}$ and 125 $\mathrm{nM}$ of Aptazyme 2.20-5 , inhibited with $250 \mathrm{nM}$ of Inhibitor 2 . Then, several concentrations $(0,15.5,31,62,124$, and 248 $\mathrm{nM}$ ) of either thrombin and $\mathrm{NA}_{2}$, or $\mathrm{NA}_{1}$ and $\mathrm{NA}_{2}$ were added in the solution. After adding $375 \mathrm{nM}$ of each substrate, the fluorescence was measured as previously explained.

Building calibration curves and data analysis For all experiments involving the measurement of the DNAzyme or the aptazyme activity, a solution containing only the corresponding substrate, or combination of substrates, was used to normalize the measured fluorescence intensity. The difference between the conditions tested was analyzed with a one-way ANOVA followed by a Tukey test for multiple comparisons.

Calibration curves were composed using the normalized fluorescence intensity at $7 \mathrm{~min}$ after the start of the reaction and subtracting the background intensity (in the absence of target) for each repetition. Limit of detection (LOD) values for different competitive bioassays were calculated based on the signal of the background plus three standard deviations. Finally, the difference between the singleplex and multiplex LOD was evaluated with a two-sided T-test with significance level alpha equal to $5 \%$. The statistical analysis was performed in Python 3.7 using the scipy and statsmodels packages.

\section{Results and discussion}

\section{Screening of buffers for the optimal Aptazyme ${ }_{1.15-3}$, performance}

In order to have a functional Aptazyme ${ }_{1.15-3}$, for developing a competitive bioassay, we first needed to select the most optimal buffer conditions, permitting both efficient TBA interaction with its thrombin target and efficient DNAzyme catalytic activity. Several studies have reported the presence of $\mathrm{K}^{+}$ions as stabilizers of the TBA guanosine $(\mathrm{G})$-quadruplex structure $[31,32]$. Moreover, the DNAzyme requires the presence of the $\mathrm{Mg}^{2+}$ as a cofactor to express cleavage activity [18]. Therefore, to meet the needs of both aptazyme elements, we selected three candidate buffers from literature containing both $\mathrm{K}^{+}$and $\mathrm{Mg}^{2+}$ ions, but with different components and $\mathrm{pH}$ values [33-35] (referred to in this paper as Buffer $_{\mathrm{A}}$, Buffer $_{B}$, and Buffer ${ }_{C}$; for composition, see Table 1).

Although several TBAs have been discovered to date, only two are frequently used, $\mathrm{TBA}_{15}$ and $\mathrm{TBA}_{28}[36,37]$, both of which undergo a similar secondary conformation based on an intramolecular G-quadruplex despite differing in length. To select one for establishing the competitive bioassay, we first tested their interaction with several thrombin concentrations $(0,62,124$, and $248 \mathrm{nM})$ in Buffer $_{\mathrm{A}}$, Buffer $_{\mathrm{B}}$, and Buffer $\mathrm{C}$. This was done on a FO-SPR sensor, commercialized by FOx Biosystems (a platform based on an in-house developed technology [29, 30]), by immobilizing thiol-modified aptamers on the FO-SPR probes (Fig. S2). As depicted in Fig. 2A (TBA 15$)$ and Fig. S3 in ESM $\left(\mathrm{TBA}_{28}\right), \mathrm{TBA}_{15}$ showed overall more consistent interaction with thrombin across different concentrations and buffers and was selected as the preferred aptamer in this context. In addition, we observed no statistically significant differences for $\mathrm{TBA}_{15}$-thrombin interaction among Buffer $_{A}$, Buffer $_{B}$, and Buffer ${ }_{C}$ (based on a one-way ANOVA followed by a Tukey test). Interestingly, we have also tested in the same context the DNAzyme buffer, which seemed not to be suitable for the interaction of $\mathrm{TBA}_{15}$ with thrombin, despite having the same components as the other
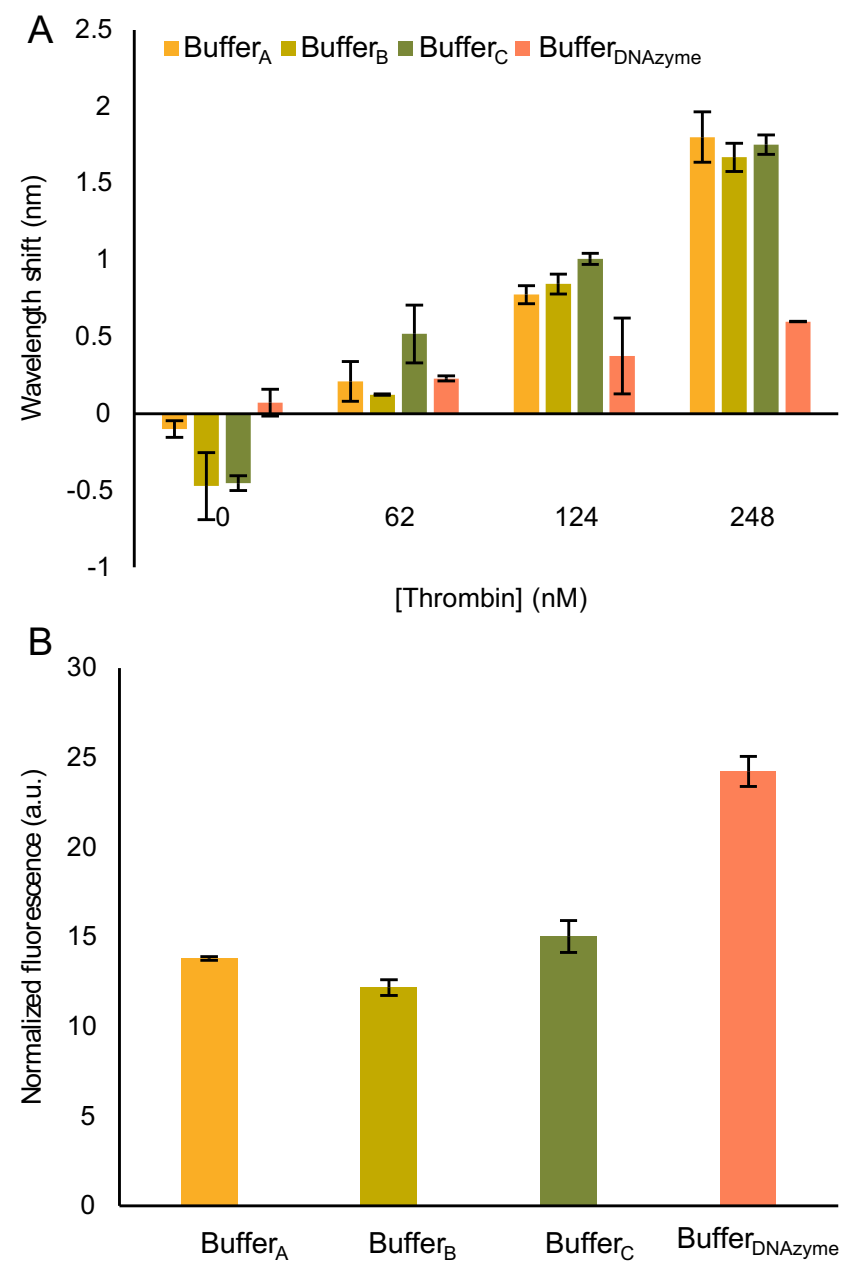

Fig. 2 Performance of the aptazyme components in various buffers. A Performance of $\mathrm{TBA}_{15}$, immobilized on the FO-SPR sensor, obtained by measuring the wavelength shift in the presence of a dilution series of thrombin. B Fluorescence signal generated by DNAzyme ${ }_{1}(250 \mathrm{nM})$ in the presence of Substrate $_{1}(250 \mathrm{nM})$ as measured on the microplate reader. The error bars in $\mathbf{A}$ and $\mathbf{B}$ represent the standard deviations of two and three repetitions, respectively 
buffer candidates. These results could be explained by the previously reported decrease in performance of TBA at high $\mathrm{Mg}^{2+}$ concentrations [38, 39].

For assessing DNAzyme ${ }_{1}$ activity in Buffer $_{\mathrm{A}}, \mathrm{Buffer}_{\mathrm{B}}$, and Buffer $_{C}$, we used a microplate reader as explained in the "Materials and methods." Among the three candidate buffers, we only observed a statistical difference between Buffer $_{B}$ and Buffer ${ }_{C}$, based on a one-way ANOVA with

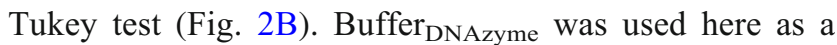
positive reference and expectedly showed the highest signal, due to the highest concentration of $\mathrm{Mg}^{2+}$ in this buffer. However, because of the complete absence of TBA interaction with thrombin in this buffer (Fig. 2A), it could not be taken into account for developing competitive bioassays with aptazymes. Therefore, Buffer $_{\mathrm{A}}$ was selected for all the subsequent experiments, based on (1) Fig. 2A and Fig. 2B, (2) the fact that $\mathrm{Buffer}_{\mathrm{A}}$ has the same $\mathrm{pH}$ (8.3) like the reference buffer for DNAzyme and (3) the same $\mathrm{pH}$ like TGK buffer used for optimal binding of TBA aptamer [40] $(50 \mathrm{mM}$ Tris, $192 \mathrm{mM}$ glycine and $5 \mathrm{mM} \mathrm{K}_{2} \mathrm{HPO}_{4}, 0.1 \% \mathrm{v} / \mathrm{v}$ Tween 20 and $0.15 \% \mathrm{w} / \mathrm{v}$ BSA, pH 8.3).

Next, we independently verified the functionality of $\mathrm{TBA}_{15}$ and DNAzyme ${ }_{1}$ when combined in Aptazyme ${ }_{1.15-3}$. To test the aptamer functionality, Aptazyme 1.15-3 , was immobilized on FO-SPR probes and its binding to thrombin $(0,62,124$, and $248 \mathrm{nM}$ ) was monitored using Buffer $_{\mathrm{A}}$ (Fig. 3A). The results showed a superior binding of $\mathrm{TBA}_{15}$ within Aptazyme $_{1.15-3}$, compared to the control $\mathrm{TBA}_{15}$ immobilized on the FO-SPR probes, especially pronounced at higher thrombin concentrations. This improvement could be due to a reduction of the steric hindrance, and an increased spatial freedom for $\mathrm{TBA}_{15}$ to adopt its secondary conformation within Aptazyme 1.15-3 because DNAzyme ${ }_{1}$ acts as a sort of a linker (Fig. S2, ESM).

In parallel, we compared the cleaving activity of Aptazyme $_{1.15-3}$, to that of DNAzyme ${ }_{1}$ by measuring the fluorescence signal increase after the addition of Substrate ${ }_{1}$ (Fig. 3B and ESM Fig. S4 for the signal increase over time). In this case, the results showed an inferior fluorescence intensity for Aptazyme ${ }_{1.15-3}$. According to the literature, the quantum yield of a fluorescence reporter can be affected by the contiguous nucleobases, with $\mathrm{G}$ having the greatest impact $[41,42]$. Given that $\mathrm{TBA}_{15}$ contains $60 \%$ of $\mathrm{G}$, we replaced its sequence within Aptazyme ${ }_{1.15-3}$, with a PolyT of the same length (Aptazyme ${ }_{1 . \text { PolyT }}$, $\mathrm{nr} 7$ in Table S1, ESM) and measured its cleaving activity. Here, the same signal was obtained for both the DNAzyme ${ }_{1}$ and the Aptazyme ${ }_{1 . \text { PolyT }}$ (Fig. 3B), suggesting that the decrease in the signal of Aptazyme 1.15-3, , was probably due to G-mediated quenching of fluorescence. Therefore, we decided to proceed with Aptazyme ${ }_{1.15-3}$, without any further optimization of its DNAzyme ${ }_{1}$ activity.
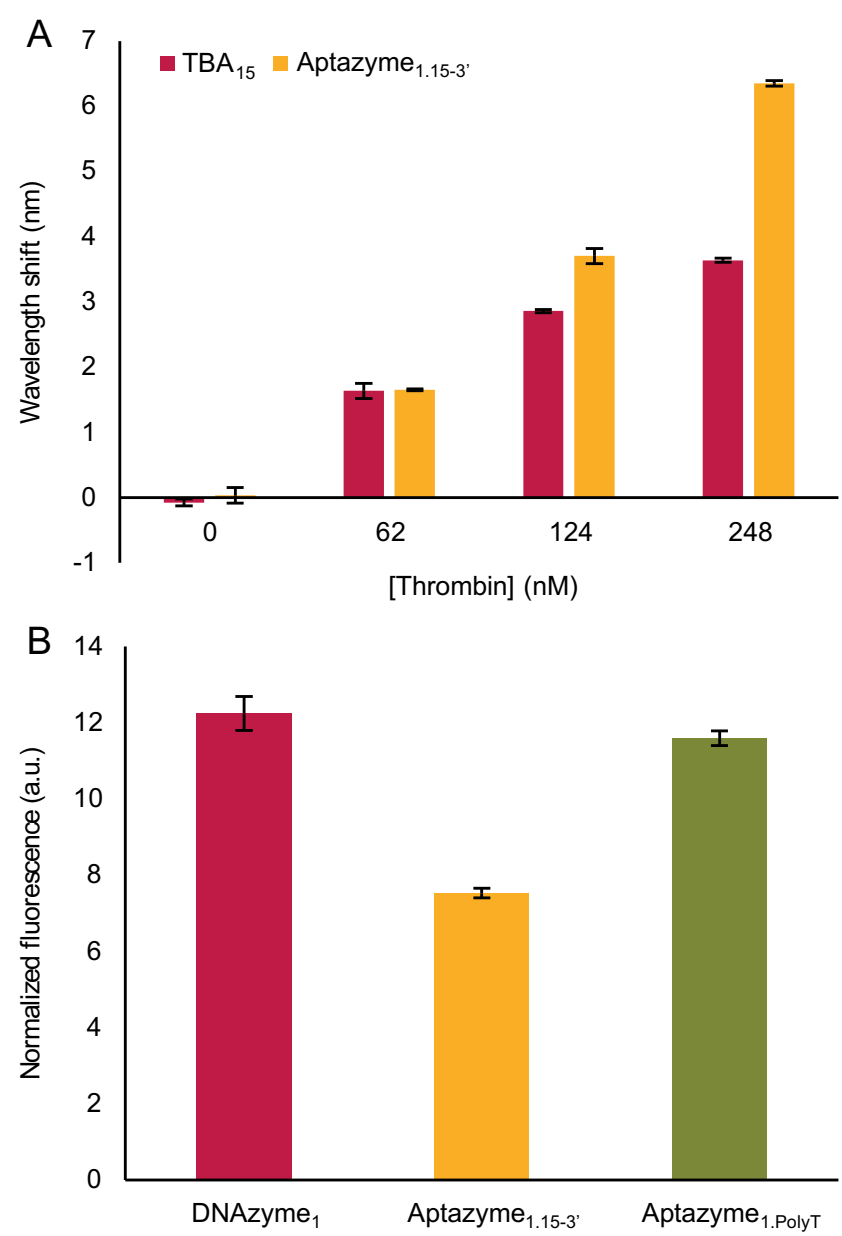

Fig. 3 Validation of the functionality of $\mathrm{TBA}_{15}(\mathbf{A})$ and DNAzyme ${ }_{1}(\mathbf{B})$ within the hybrid Aptazyme 1.15-3, . A FO-SPR probes were functionalized

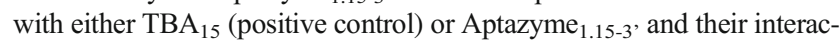
tion with thrombin at different concentrations was monitored by a shift in the resonance wavelength. B The performance of DNAzyme ${ }_{1}$ within the hybrid Aptazyme 1.15- $_{3}$, and Aptazyme ${ }_{1 . \text { PolyT }}$, the latter having $\mathrm{TBA}_{15}$ replaced with a PolyT of the same length, was validated by measuring the fluorescence intensity of the cleaved $\mathrm{F} / \mathrm{Q}$ - labelled Substrate $_{1}$ and compared to the original DNAzyme ${ }_{1}$ activity. Aptazyme ${ }_{1.15-3}$, or DNAzyme $_{1}$ and Substrate ${ }_{1}$ were used in these experiments at $250 \mathrm{nM}$ concentration each. The error bars in $\mathbf{A}$ and $\mathbf{B}$ represent the standard deviation of two and three repetitions, respectively

\section{Development of DNA-only competitive bioassay for thrombin and NA target detection}

To establish a competitive bioassay as depicted in Fig. 1, we first had to determine the optimal length of the inhibitory sequence. Here, we considered the percentage of the DNAzyme $_{1}$ and $\mathrm{TBA}_{15}$ sequence within Aptazyme ${ }_{1.15-3}$, that had to be blocked in order to, on one hand, maintain DNAzyme $_{1}$ inhibition as stable as possible in the absence of thrombin, but on the other hand allow removal of the inhibitor upon addition of thrombin. In this context, we evaluated the blocking efficiency of two inhibitory sequences covering either the substrate binding arm of DNAzyme ${ }_{1}$ alone or in conjunction with three bases of the core as well (respectively, 
Inhibitor $_{1 \mathrm{~A}}$ and Inhibitor ${ }_{1 \mathrm{~B}}$, corresponding to $\mathrm{nr} 14$ and 15 in Table S1, ESM) (Fig. 4A). It is important to note that both sequences blocked four nts of $\mathrm{TBA}_{15}$, which was based on the previous work demonstrating that blocking $26 \%$ of the aptamer results in a low background and a significant detection of thrombin at low temperatures [43].

In a first attempt, $250 \mathrm{nM}$ of Aptazyme ${ }_{1.15-3}$, was incubated with each inhibitory sequence in a 1:10 ratio (i.e., $2500 \mathrm{nM}$ ) for 15 and $30 \mathrm{~min}$ and the generated fluorescence signal was measured after adding $250 \mathrm{nM}$ of Substrate $_{1}$ (Fig. 4B).

A

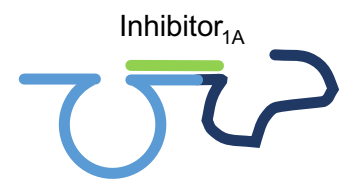

B
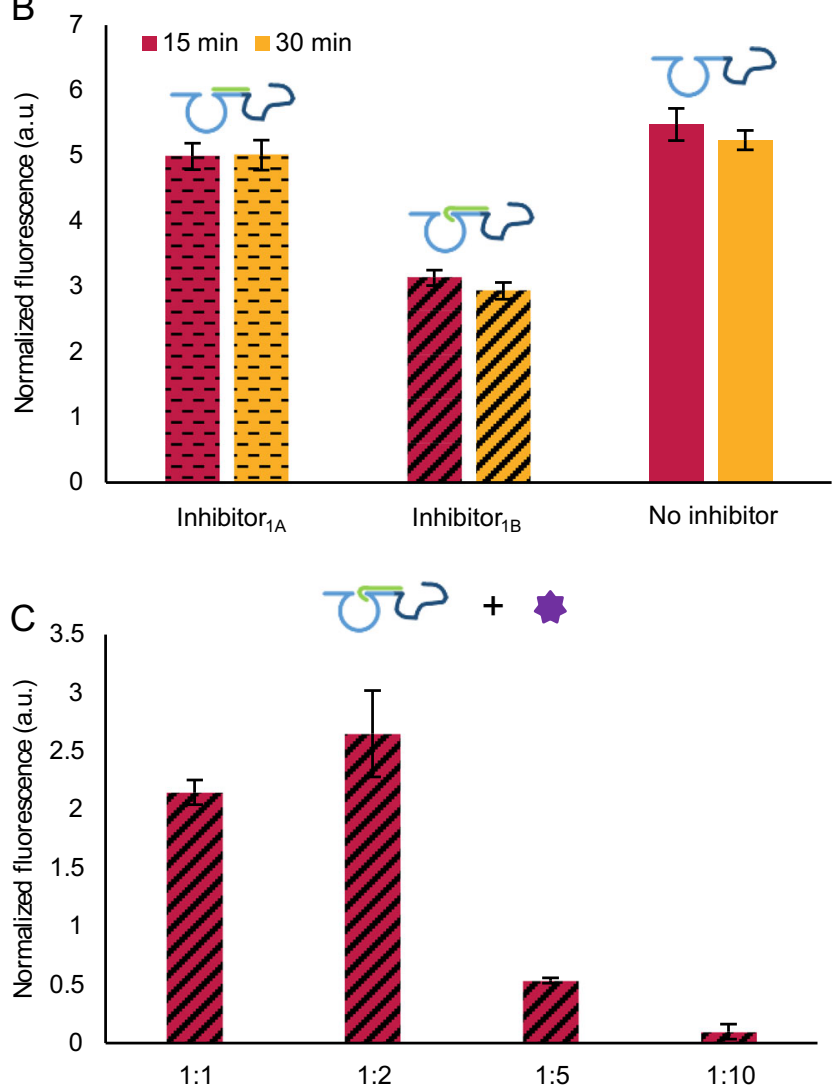

Fig. 4 Optimization of the inhibition of Aptazyme ${ }_{1.15-3}$. A Schematic representation of the two inhibitory sequences, Inhibitor ${ }_{1 \mathrm{~A}}$ and Inhibitor $_{1 \mathrm{~B}}$. B Testing two inhibitory sequences at two hybridization times (15 and $30 \mathrm{~min}$ ) at $250 \mathrm{nM}$ of Aptazyme ${ }_{15-3}$, and $2500 \mathrm{nM}$ of Inhibitor $_{1 \mathrm{~A}}$ or Inhibitor ${ }_{1 \mathrm{~B}}$. The generated fluorescence signal was recorded upon addition of $250 \mathrm{nM}$ of Substrate ${ }_{1}$. C Testing the capacity of thrombin $(248 \mathrm{nM})$ to reactivate Aptazyme ${ }_{1.15-3}$, inhibited with Inhibitor $_{1 \mathrm{~B}}$ in different ratios $(1: 1,1: 2,1: 5$, and $1: 10$, which correspond to $250 \mathrm{nM}$ of Aptazyme $_{1.15-3}:: 250,500,1250$, and $2500 \mathrm{nM}$ of Inhibitor $_{1 \mathrm{~B}}$, respectively). In this case, the signal in the absence of thrombin was subtracted from the signal in the presence of thrombin. In both graphs, the error bars represent the standard deviation of three repetitions. The description of the fluorescence normalization process can be found in "Materials and methods" section
Regardless of the incubation time, the obtained fluorescence signal when using Inhibitor ${ }_{1 \mathrm{~A}}$ was comparable to the noninhibited Aptazyme ${ }_{1.15-3^{\prime}}$, meaning that covering only the substrate binding arm of DNAzyme ${ }_{1}$ was not sufficient to prevent the cleavage of substrate. Contrary to this, covering part of the catalytic core in addition to the substrate binding arm resulted in half of the signal when compared with the non-inhibited Aptazyme $_{1.15-3}$, without significant difference between two tested times. Consequently, we selected Inhibitor ${ }_{1 \mathrm{~B}}$ and shorter incubation $(15 \mathrm{~min})$ for further optimization in the following experiments.

In a next step, we tested the ability of thrombin to remove the inhibitor and as such reactivate DNAzyme ${ }_{1}$ within Aptazyme $_{1.15-3}$, (Fig. 4C). Therefore, $248 \mathrm{nM}$ of thrombin (the highest concentration tested on the FO-SPR device, see Figs. 2 and 3) and the same concentration of Substrate ${ }_{1}$ as in the previous experiment $(250 \mathrm{nM})$ were added to the inhibited Aptazyme $_{1.15-3}$ '. Here, in parallel, we also investigated other ratios between the aptazyme and the inhibitor, rather than just 1:10 tested in Fig. 4B, being 1:1, 1:2, and 1:5. Although thrombin was capable of reactivating inhibited Aptazyme $_{1.15-3}$, for all the ratios, this success was clearly different among tested conditions. The one-way ANOVA with Tukey test showed a statistical difference between 1:2 and the other ratios, except for 1:1. However, based on the higher average value obtained for the 1:2 ratio compared to $1: 1$, the former was selected for all the subsequent experiments. After additional optimization of Aptazyme ${ }_{1.15-3}$, and Substrate $_{1}$ concentrations, we selected $250 \mathrm{nM}$ of Aptazyme ${ }_{1.15-3}$, and 750 $\mathrm{nM}$ of Substrate ${ }_{1}$ to proceed (Fig. S5, ESM), while keeping 1:2 ratio between aptazyme and inhibitor.

Using the optimized conditions, we tested the capacity of competitive bioassay to detect not only thrombin but an NA target as well $(0-248 \mathrm{nM})$ (Fig. 5). The latter was achieved by simply using the complementary sequence of $\mathrm{TBA}_{15}$ as a target $\left(\mathrm{NA}_{1}, \mathrm{nr} 17\right.$ in Table S1, ESM). The competitive bioassay was performed as explained above and the generated fluorescence was measured after the addition of $750 \mathrm{nM}$ of Substrate $_{1}$. For both targets, we obtained a similar concentration-dependent response, although for $\mathrm{NA}_{1}$ the overall signal intensity was higher than that for thrombin. The calculated LOD was $45.6 \pm 0.8 \mathrm{nM}$ and $14.1 \pm 0.9 \mathrm{nM}$ for thrombin and $\mathrm{NA}_{1}$, respectively.

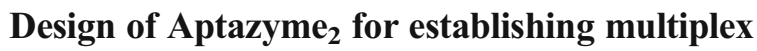 DNA-only bioassay}

After demonstrating that the same competitive bioassay concept can be used to detect both protein and NA targets separately, we attempted to detect them simultaneously in the same reaction. However, because both targets were detected in singlepex reactions using the same Aptazyme 1.15-3, , we first needed to construct a new aptazyme. Here, the original 


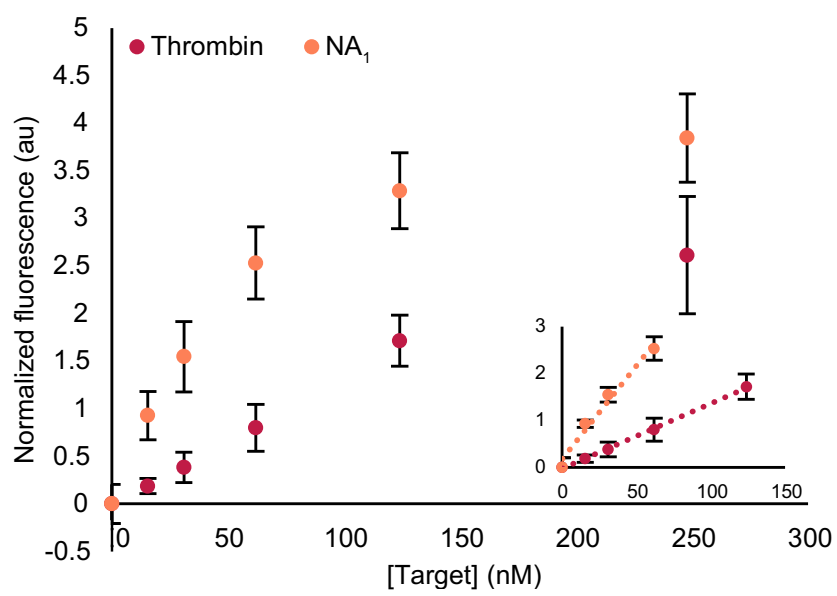

Fig. 5 Concentration-dependent response of the competitive bioassay in the presence of thrombin or $\mathrm{NA}_{1}$. The inset shows the linear range for both targets, being $0-124 \mathrm{nM}$ for thrombin $\left(\mathrm{R}^{2}=0.99\right)$ and $0-62 \mathrm{nM}$ for $\mathrm{NA}_{1}\left(\mathrm{R}^{2}=0.99\right)$. The error bars represent the standard deviation of three repetitions, whereas the LOD values have been calculated as described in the "Materials and methods" section

Aptazyme $_{1.15-3}$, was kept for thrombin detection, while a new aptazyme was designed for detecting a new NA target (i.e., $\mathrm{NA}_{2}$ ), motivated by the much easier design of a new target recognition sequence for the NA target. To achieve this, we made two changes to the original Aptazyme ${ }_{1.15-3}$. First, to fluorescently differentiate between the two targets, we modified the substrate-binding arms of DNAzyme ${ }_{1}$ for binding Substrate $_{2}$, labelled with a different fluorophore (nr 20 in Table S1, ESM), while keeping the same catalytic core. This substrate sequence was previously reported by Mokany et al. [44] and redesigned by Ven et al. for optimal performance at RT [26]. Second, we swapped the $\mathrm{TBA}_{15}$ for a random 28-mer NA sequence (nr 8 in Table S1, ESM the same bioreceptor). This resulted in generation of Aptazyme $2.28-3$ '.

Contrary to the expectations, Aptazyme $2.28-3$, was able to generate only $20 \%$ of the fluorescence signal generated by the corresponding DNAzyme ${ }_{2}$ (Fig. 6). To have a better understanding of the observed difference, we studied their secondary structures using the OligoAnalyzer 3.1 tool of IDT Technologies (https:/eu.idtdna.com/calc/analyzer) (Fig. S6A and Fig. S6B, ESM). Aptazyme ${ }_{1.15-3}$, was used here as a reference considering that the successful competitive bioassay was already accomplished with it. Based on the analysis of the most stable secondary structures, we observed that the addition of $\mathrm{TBA}_{15}$ to $\mathrm{DNAzyme}_{1}$ did not affect its secondary structure. However, Aptazyme ${ }_{2.28-3}$, had an extra hairpin compared to DNAzyme ${ }_{2}$, which was composed by part of the (1) core, (2) substrate-binding arm, and (3) target recognition sequence (highlighted as yellow, red, and blue respectively in Fig. S6B, ESM). The fact that the target recognition sequence induced a change in the secondary structure of DNAzyme ${ }_{2}$ could explain the decrease in the enzymatic activity of Aptazyme $2.28-3^{\prime}$.

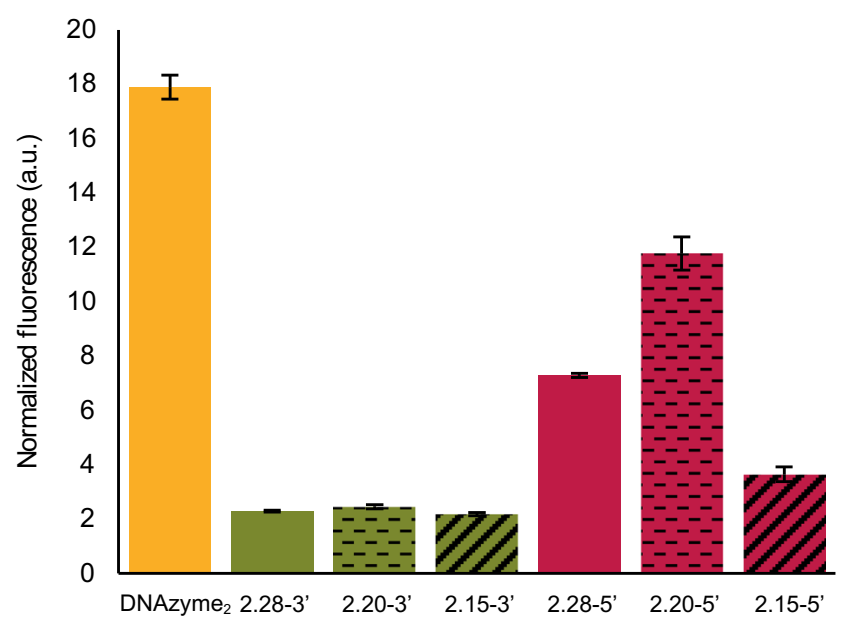

Fig. 6 Screening of different Aptazyme ${ }_{2}$ designs based on their catalytic activity in the presence of Substrate ${ }_{2}$. The influence of different lengths $(28,20$, and $15 \mathrm{nts})$ and positions (3' or 5' end of the DNAzyme ${ }_{2}$ ) of the target recognition sequences were studied. The error bars represent the standard deviation of three repetitions. Additionally, the fluorescence normalization process is described in the "Materials and methods" section

In order to develop an aptazyme of similar catalytic activity as DNAzyme ${ }_{2}$, we designed five additional aptazymes: two with target recognition sequences (20 and $15 \mathrm{nts}$ ) positioned on the 3 ' side of DNAzyme 2 and three with target recognition sequences $(28,20$, and $15 \mathrm{nts})$ on the 5 ' side (nr 8-13 in Table S1, ESM). Their secondary structures were then analyzed using the same simulation tool as above, followed by measuring their enzymatic activity. Aptazyme $2.20-3$, and Aptazyme $_{2.15-3}$, revealed similar secondary structures as Aptazyme $_{2.28-3^{\prime}}$, suggesting that the target recognition sequences positioned on the 3 ' side of DNAzyme ${ }_{2}$ affected its intrinsic conformation (Fig. S6C, ESM). This was further confirmed with the similar (low) level of enzymatic activity among these three aptazymes (Fig. 6). Contrary to this, the target recognition sequences introduced on the 5 ' side of DNAzyme $_{2}$ gave noticeable increase in the activity, which was different for all three aptazymes, while being the highest for Aptazyme $2.20-5$, that was capable of generating $66 \%$ of the signal generated by the corresponding DNAzyme ${ }_{2}$. This observed disparity in their activities could be due to their secondary structures. To understand the differences, we considered two different aspects of the secondary structure: its stability and the involvement of DNAzyme 2 in this secondary structure. For instance, while the target recognition sequence in Aptazyme $2.28-5$, created an additional hairpin involving the substrate binding arm, it did not affect the intrinsic conformation of DNAzyme 2 as in the case of Aptazyme $2.15-5$. This could be the explanation why this aptazyme showed higher activity than Aptazyme $2.15-5$, despite having a more stable secondary structure. In a similar manner, the target recognition sequence in Aptazyme $2.20-5$, generated an additional hairpin, but with a shorter stem than Aptazyme $2.28-5$, which resulted in a less stable conformation and thus higher activity. Taking all 
this into account, we can conclude that the degree to which the target recognition sequence affects the secondary structure of the DNAzyme is crucial for the aptazyme performance. This was further confirmed by the observation that, for all tested aptazymes, signal generation increased upon adding the target (data not shown), which can be explained by the fact that this target interacted with the part of the aptazyme that actually interfered with the DNAzyme activity. Importantly, however, even under these conditions, Aptazyme $2.20-5$, remained the construct with the highest activity, therefore being selected for developing the multiplex bioassay.

Before using Aptazyme $2.20-5$, directly in the multiplex bioassay, we also evaluated its performance in the competitive bioassay. Here, $250 \mathrm{nM}$ of Aptazyme $2.20-5$, was inhibited using Inhibitor ${ }_{2}$ as previously described. Subsequently, several concentrations of $\mathrm{NA}_{2}$ target were added in the range from 0 to $248 \mathrm{nM}$ together with $750 \mathrm{nM}$ of Substrate $_{2}$, followed by measuring the generated fluorescence signal for each target concentration (Fig. S7, ESM). The fitting in the linear range resulted in a LOD of $5.1 \pm 0.1 \mathrm{nM}$, similar to what was previously obtained for $\mathrm{NA}_{1}$.

\section{DNA-only multiplex bioassay for detection of thrombin and NA target or two NA targets}

To develop a multiplex bioassay, we first ensured the possibility of independently detecting both fluorescence reporters in the same solution without any interference. Therefore, we measured the intensity of Substrate ${ }_{1}$ and Substrate $_{2}$ separately and in the same solution, in both $\mathrm{F}$ and $\mathrm{H}$ channels (Fig. S8A, ESM). The fluorescence intensities observed in both channels when both substrates were present together were comparable to their independent measurements, indicating no interference between the fluorescent labels. In the next step, to corroborate the specificity of each aptazyme for its substrate, we measured the fluorescence signal generated by each aptazyme separately and in the same solution, in the presence of both substrates (Fig. S8B, ESM, observing no non-specific signal generation). Following this, we evaluated the specificity of the multiplex approach in terms of the bioreceptors. Hereto, we measured the fluorescence signal generated by the $125 \mathrm{nM}$ of Aptazyme $_{1.15-3}$, or Aptazyme $2.20-5$, respectively inhibited with $250 \mathrm{nM}$ of Inhibitor ${ }_{1 \mathrm{~B}}$ or Inhibitor 2 prior to adding each individual target $\left(248 \mathrm{nM}\right.$ of thrombin or $\mathrm{NA}_{2}$ ) or both targets together in the same reaction (Fig. 7A). In parallel, we also performed a similar experiment to determine the bioreceptor specificity when detecting two NA targets (Fig. 7B). In all these experiments, both Substrate $_{1}$ and Substrate Sue $_{2}$ were always added together, each at $375 \mathrm{nM}$ concentration. The results revealed high specificity of the bioreceptors towards their respective targets in both tested bioassays. All this also pointed out that the observed interactions are not promoted by the buffer selection, but are a reflection of the specific interactions between the aptazymes and their respective NA targets.

Finally, we evaluated the multiplex detection of thrombin and $\mathrm{NA}_{2}$ over the concentration range from 0 to $248 \mathrm{nM}$ using Aptazyme $_{1.15-3}$, and Aptazyme $2.20-5$, (each at $125 \mathrm{nM}$ ), inhibited with $250 \mathrm{nM}$ of their respective inhibitors prior to adding the rest of the bioassay components. In the same manner, we attempted the simultaneous detection of $\mathrm{NA}_{1}$ and $\mathrm{NA}_{2}$. In both cases, we monitored the fluorescence intensity after the addition of Substrate and Substrate $_{2}$, each at $375 \mathrm{nM}$ concentration (Fig. 7C and Fig. 7D). The performed multiplex bioassays revealed LOD values in the $\mathrm{nM}$ range like the singleplex versions of the same bioassay (Table 2). The former, however, showed slightly lower LOD values for all targets, except for $\mathrm{NA}_{2}$ when detected together with $\mathrm{NA}_{1}$ (statistically significant as evaluated with a T-test). This improvement in LOD for the multiplex measurements could be attributed to the lower variability observed for the blank measurements, which was not the case for $\mathrm{NA}_{2}$ in the $\mathrm{NA}_{1}$ and $\mathrm{NA}_{2}$ multiplexing. Another possible explanation could be because of the reduced concentrations of each reaction component to half in the multiplexing bioassay in order to maintain the total amount of reaction elements in the solution. Nevertheless, taken altogether, these results revealed that the developed bioassay can be successfully performed both in singleplex and multiplex formats with sensitivities in the nM range. This is in accordance with similar reported LOD values for other aptazymes (including those with a different catalytic cores), ranging from $6.9 \mathrm{pM}$ to $18 \mu \mathrm{M}$ when using fluorescencebased read-out $[25,45,46]$.

In the case of $\mathrm{NA}_{2}$, two LODs were calculated: one from the multiplex bioassay for thrombin and $\mathrm{NA}_{2}(*)$ and the other one from $\mathrm{NA}_{1}$ and $\mathrm{NA}_{2}(* *)$

\section{Conclusions}

In the present work, we have shown for the first time the simultaneous detection of proteins and NAs in a competitive bioassay by using exclusively FNA molecules, i.e., aptazymes, which combine target recognition and signal generation in a single molecule. To attain this, we first screened several buffer compositions for preserving the optimal performance of both the aptamer and the DNAzyme within Aptazyme $_{1.15-3}$, followed by establishing the optimal concentrations for all the bioassay components. Subsequently, we successfully proved the feasibility to detect both thrombin and $\mathrm{NA}_{1}$ target in a singleplex competitive bioassay with calculated LOD values of $45.6 \pm 0.8 \mathrm{nM}$ and $14.1 \pm 0.9 \mathrm{nM}$, respectively. Next, for achieving multiplexing, we modified the Aptazyme ${ }_{1.15-3}$, by replacing the substrate binding arms of the DNAzyme and target recognition sequence. Here, we successfully designed aptazymes without affecting their catalytic 

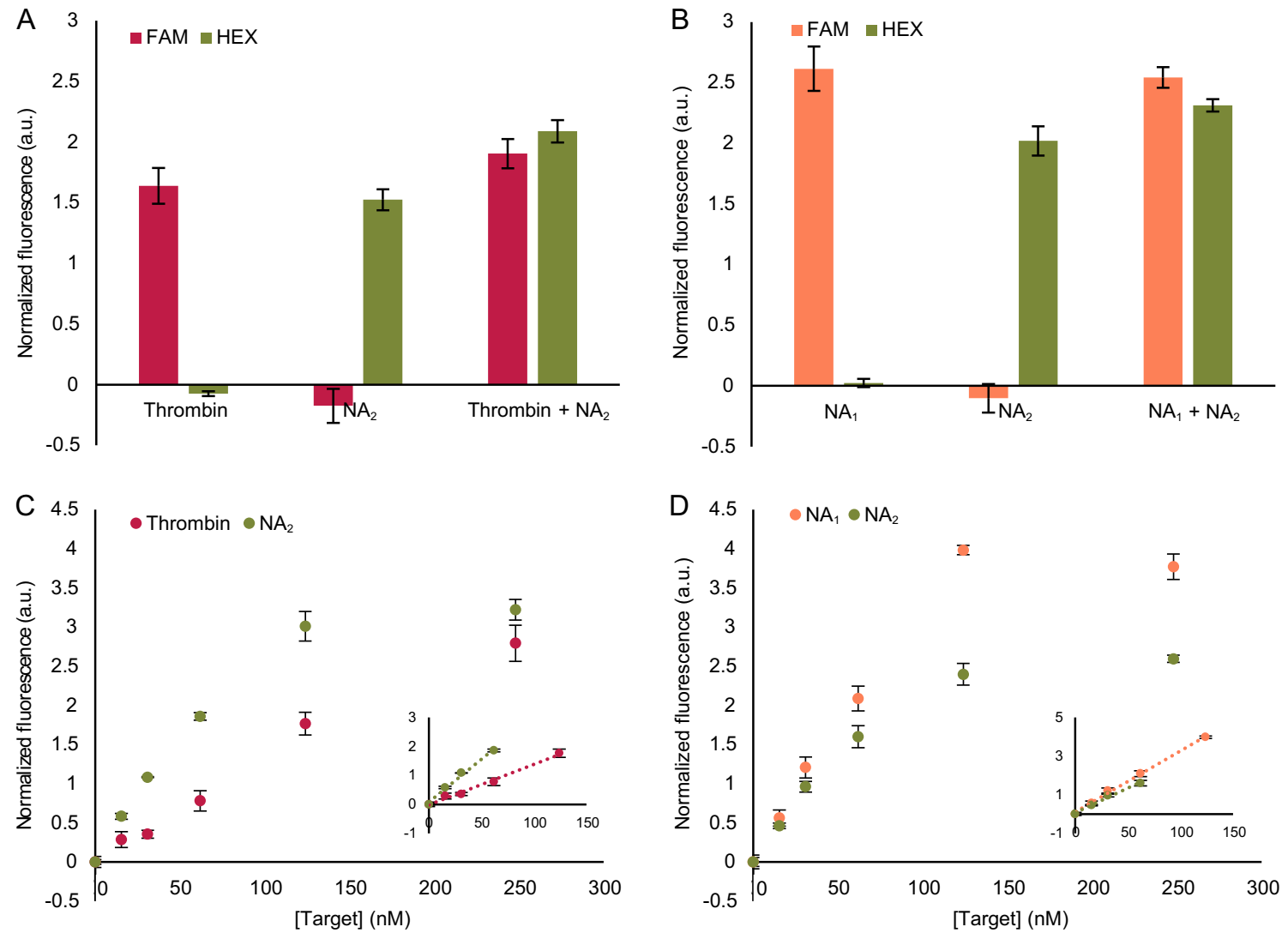

Fig. 7 DNA-only multiplex bioassay for simultaneous detection of different targets. Evaluation of the bioreceptor specificity in multiplex conditions using A $248 \mathrm{nM}$ of thrombin and $\mathrm{NA}_{2}$ as targets, and $\mathbf{B} 248$ $\mathrm{nM}$ of $\mathrm{NA}_{1}$ and $\mathrm{NA}_{2}$ as targets. $\mathbf{C}$ Concentration-dependent response for the detection of thrombin and $\mathrm{NA}_{2}$. Inset figure represents the linear range of thrombin between 0 and $124 \mathrm{nM}\left(\mathrm{R}^{2}=0.99\right)$ and of $\mathrm{NA}_{2}$ between 0

activity based on the in silico analysis of their secondary structures. From the study of several aptazyme sequences, we concluded that the activity of the DNAzyme within an aptazyme can be strongly impacted by the interference of the target recognition sequence with the DNAzyme secondary structure. By using this prediction tool, we designed a new aptazyme, Aptazyme 2.20-5, for detecting $\mathrm{NA}_{2}$ target with an LOD of 5.1 $\pm 0.1 \mathrm{nM}$ in a singleplex bioassay. Finally, we combined both Aptazyme $_{1.15-3}$, and Aptazyme ${ }_{2.20-5}$, in the same solution for the simultaneous detection of thrombin and $\mathrm{NA}_{2}$ target or $\mathrm{NA}_{1}$

Table 2 Overview of the obtained LOD values in the different bioassays established in this work, as depicted in Fig. 1

\begin{tabular}{lll}
\hline & Singleplex & Multiplex \\
\hline Thrombin & $45.6 \pm 0.8 \mathrm{nM}$ & $15.6 \pm 0.5 \mathrm{nM}$ \\
$\mathrm{NA}_{1}$ & $14.1 \pm 0.9 \mathrm{nM}$ & $7.5 \pm 0.3 \mathrm{nM}$ \\
$\mathrm{NA}_{2}$ & $5.1 \pm 0.1 \mathrm{nM}$ & $3.1 \pm 0.1^{*} / 6.4 \pm 0.3 \mathrm{nM}^{* *}$ \\
\hline
\end{tabular}

and $\mathrm{NA}_{2}$. In these multiplex bioassays, we demonstrated the high specificity of each aptazyme with no decrease in the bioassay efficiency compared to their performance in the singleplex bioassay. Although previous studies have reported the detection of thrombin [46-48] or various NA targets [49-51] with picomolar or even femtomolar sensitivities, many of those approaches required elevated temperatures and/or longer assay time ( $30 \mathrm{~min}-5 \mathrm{~h})$. Contrary to this, the approach we presented in this work not only is capable of detecting the targets at RT within $10 \mathrm{~min}$, but is also unique in its capacity to detect multiple targets, regardless of their origin or chemical nature, using the same bioassay components and the same read-out method. Considering this premise, such a multiplex bioassay could be conveniently modified for different targets of interest, by replacing the aptamer or target recognition sequence. Similarly, the number of targets could be increased by incorporating new substratebinding arms of the DNAzyme. Furthermore, due to the advantages associated to the NA nature of the bioassay, the possibility to work at RT, and the short assay time, this 
approach could be a good candidate for further implementation in POC platforms.

Supplementary Information The online version contains supplementary material available at https://doi.org/10.1007/s00216-021-03458-6.

Acknowledgements This work has received funding from European Union's Horizon 2020 research and innovation programme under the Marie Skłodowska-Curie grant agreement No 675412 (H2020-MSCAITN-ND4ID), the KU Leuven (postdoctoral mandate Saba Safdar PDM/ 20/080, research project C3/20/057), and the Research Foundation -Flanders (FWO SB/1S30116N, Research Project G042918N).

\section{Declarations}

Conflict of interest The authors declare no competing interests.

\section{References}

1. Souf S. Recent advances in diagnostic testing for viral infections. Biosci Horiz. 2016. https://doi.org/10.1093/biohorizons/hzw010.

2. Etzioni R, Urban N, Ramsey S, McIntosh M, Schwartz S, Reid B, et al. The case for early detection. Nat Rev Cancer. 2003. https:// doi.org/10.1038/nrc1041.

3. Shipp G. Ultrasensitive measurement of protein and nucleic acid biomarkers for earlier disease detection and more effective therapies clinical decision making stands to benefit from ultrasensitive molecular diagnostic. Biotechnol Healthc. 2006.

4. Langelier C, Kalantar KL, Moazed F, Wilson MR, Crawford ED, Deiss $\mathrm{T}$, et al. Integrating host response and unbiased microbe detection for lower respiratory tract infection diagnosis in critically ill adults. Proc Natl Acad Sci. 2018. https://doi.org/10.1073/pnas. 1809700115

5. Vemula SV, Zhao J, Liu J, Xue XW, Biswas S, Hewlett I. Current approaches for diagnosis of influenza virus infections in humans. Viruses. 2016. https://doi.org/10.3390/v8040096.

6. Flamini E, Mercatali L, Nanni O, Calistri D, Nunziatini R, Zoli W, et al. Free DNA and carcinoembryonic antigen serum levels: an important combination for diagnosis of colorectal cancer. Clin Cancer Res. 2006. https://doi.org/10.1158/1078-0432.CCR-061931.

7. Khan K, Aslam MA, Zahra FT, Bashir H, Bilal M, Sumrin A. Potential biomarkers for the diagnosis of respiratory tract infection and lungs cancer. Cell Mol Biol. 2017. https://doi.org/10.14715/ $\mathrm{cmb} / 2017.63 .11 .9$.

8. Yan Y, Ma C, Tang Z, Chen M, Zhao H. A novel fluorescent assay based on DNAzyme-assisted detection of prostate specific antigen for signal amplification. Anal Chim Acta. 2020. https://doi.org/10. 1016/j.aca.2020.01.014.

9. Li Y, Lu Y. Functional nucleic acids for analytical applications. Springer New York. 2009. https://doi.org/10.1021/ja905562z.

10. Xiao X, Zhu L, He W, Luo Y, Xu W. Functional nucleic acids tailoring and its application. TrAC-Trends Anal Chem. 2019. https://doi.org/10.1016/j.trac.2019.05.027.

11. Gold L, Tuerk C. Systematic evolution of ligands by exponential enrichment: RNA ligands to bacteriophage T4 DNA polymerase. Science. 1990. https://doi.org/10.1126/science.2200121.

12. Chen A, Yang S. Replacing antibodies with aptamers in lateral flow immunoassay. Biosens Bioelectron. 2015. https://oi.org/10.1016/ j.bios.2015.04.041.
13. Song S, Wang L, Li J, Fan C, Zhao J. Aptamer-based biosensors. TrAC - Trends Anal Chem. 2008. https://doi.org/10.1016/j.trac. 2007.12.004.

14. Breaker RR, Joyce GF. A DNA enzyme that cleaves RNA. Chem Biol. 1994. https://doi.org/10.1016/1074-5521(94)90014-0.

15. Zhu X, Gao X, Liu Q, Lin Z, Qiu B, Chen G. Pb2+-introduced activation of horseradish peroxidase (HRP)-mimicking DNAzyme. Chem Commun. 2011. https://doi.org/10.1039/ c1cc11349f.

16. Camden AJ, Walsh SM, Suk SH, Silverman SK. DNA oligonucleotide 3'-phosphorylation by a DNA enzyme. Biochemistry. 2016. https://doi.org/10.1021/acs.biochem.6b00151.

17. Yin H, Kuang H, Liu L, Xu L, Ma W, Wang L, et al. A ligation Dnazyme-induced magnetic nanoparticles assembly for ultrasensitive detection of copper ions. ACS Appl Mater Interfaces. 2014. https://doi.org/10.1021/am405482a.

18. Santoro SW, Joyce GF. A general purpose RNA-cleaving DNA enzyme. Biochemistry. 1997. https://doi.org/10.1073/pnas.94.9. 4262.

19. McGhee CE, Loh KY, Lu Y. DNAzyme sensors for detection of metal ions in the environment and imaging them in living cells. Curr Opin Biotechnol. 2017. https://doi.org/10.1016/j.copbio. 2017.03.002.

20. Gong L, Zhao Z, Lv YF, Huan SY, Fu T, Zhang XB, et al. DNAzyme-based biosensors and nanodevices. Chem Commun. 2015. https://doi.org/10.1039/c4cc06855f.

21. Achenbach JC, Nutiu R, Li Y. Structure-switching allosteric deoxyribozymes. Anal Chim Acta. 2005. https://doi.org/10.1016/ j.aca.2004.03.080.

22. Rossetti M, Porchetta A. Allosterically regulated DNA-based switches: from design to bioanalytical applications. Anal Chim Acta. 2018. https://doi.org/10.1016/j.aca.2017.12.046.

23. Liu X, Wang F, Aizen R, Yehezkeli O, Willner I. Graphene oxide/ nucleic-acid-stabilized silver nanoclusters: functional hybrid materials for optical aptamer sensing and multiplexed analysis of pathogenic DNAs. J Am Chem Soc. 2013. https://doi.org/10.1021/ ja403485r.

24. Zhang L, Guo S, Zhu J, Zhou Z, Li T, Li J, et al. Engineering DNA three-way junction with multifunctional moieties: sensing platform for bioanalysis. Anal Chem. 2015. https://doi.org/10.1021/acs. analchem.5b02468.

25. Huang J, He Y, Yang XH, Quan K, Wang KM. Inhibited aptazymebased catalytic molecular beacon for amplified detection of adenosine. Chin Chem Lett. 2014. https://doi.org/10.1016/j.cclet.2014. 05.039 .

26. Ven K, Safdar S, Dillen A, Spasic D, Lammertyn J. Re-engineering 10-23 core DNA- and MNAzymes for applications at standard room temperature. Anal Bioanal Chem. 2018. https://doi.org/10. 1007/s00216-018-1429-4.

27. Deng B, Lin Y, Wang C, Li F, Wang Z, Zhang H, et al. Aptamer binding assays for proteins: the thrombin example-a review. Anal Chim Acta. 2014. https://doi.org/10.1016/j.aca.2014.04.055.

28. Yin HS, Li BC, Zhou YL, Wang HY, Wang MH, Ai SY. Signal-on fluorescence biosensor for microRNA-21 detection based on DNA strand displacement reaction and $\mathrm{Mg} 2+$-dependent DNAzyme cleavage. Biosens Bioelectron. 2017. https://doi.org/10.1016/j. bios.2017.04.049.

29. Peeters B, Daems D, Van Der Donck T, Delport F, Lammertyn J. Real-time FO-SPR monitoring of solid-phase DNAzyme cleavage activity for cutting-edge biosensing. ACS Appl Mater Interfaces. 2019. https://doi.org/10.1021/acsami.8b18756.

30. Daems D, Peeters B, Delport F, Remans T, Lammertyn J, Spasic D. Identification and quantification of celery allergens using fiber optic surface plasmon resonance PCR. Sensors. 2017. https://doi.org/10. 3390/s17081754. 
31. Marathias VM, Bolton PH. Determinants of DNA quadruplex structural type: sequence and potassium binding. Biochemistry. 1999. https://doi.org/10.1021/bi982604+.

32. Tan SY, Acquah C, Tan SY, Ongkudon CM, Danquah MK. Characterisation of charge distribution and stability of aptamerthrombin binding interaction. Process Biochem. 2017. https://doi. org/10.1016/j.procbio.2017.06.003.

33. Nutiu R, Li Y. Structure-switching signaling aptamers. J Am Chem Soc. 2003. https://doi.org/10.1021/ja028962o.

34. Li N, Ho CM. Aptamer-based optical probes with separated molecular recognition and signal transduction modules. J Am Chem Soc. 2008. https://doi.org/10.1021/ja076787b.

35. Tang Z, Mallikaratchy P, Yang R, Kim Y, Zhu Z, Wang H, et al. Aptamer switch probe based on intramolecular displacement. J Am Chem Soc. 2008. https://doi.org/10.1021/ja804119s.

36. Bock LC, Griffin LC, Latham JA, Vermaas EH, Toole JJ. Selection of single-stranded DNA molecules that bind and inhibit human thrombin. Nature. 1992.

37. Tasset DM, Kubik MF, Steiner W. Oligonucleotide inhibitors of human thrombin that bind distinct epitopes. J Mol Biol. 1997. https://doi.org/10.1006/jmbi.1997.1275.

38. Kang Y, Feng KJ, Chen JW, Jiang JH, Shen GL, Yu RQ. Electrochemical detection of thrombin by sandwich approach using antibody and aptamer. Bioelectrochemistry. 2008. https://doi.org/ 10.1016/j.bioelechem.2008.04.024.

39. Baldrich E, Restrepo A, O'Sullivan CK. Aptasensor development: elucidation of critical parameters for optimal aptamer performance. Anal Chem. 2005. https://doi.org/10.1021/ac049258o.

40. Buchanan DD, Jameson EE, Perlette J, Malik A, Kennedy RT. Effect of buffer, electric field, and separation time on detection of aptamer-ligand complexes for affinity probe capillary electrophoresis. Electrophoresis. 2003. https://doi.org/10.1002/elps.200390176.

41. Behlke MA, Huang L, Bogh L, Rose S, Devor EJ. Fluorescence quenching by proximal G-bases. Integr DNA Technol. 2005.

42. Mao H, Luo G, Zhan Y, Zhang J, Yao S, Yu Y. The mechanism and regularity of quenching the effect of bases on fluorophores: the base-quenched probe method. Analyst. 2018. https://doi.org/10. 1039/c8an00116b.

43. Nutiu R, Li Y. Structure-switching signaling aptamers: transducing molecular recognition into fluorescence signaling. Chem - A Eur J. 2004. https://doi.org/10.1002/chem.200305470.
44. Mokany E, Bone SM, Young PE, Doan TB, Todd AV. MNAzymes, a versatile new class of nucleic acid enzymes that can function as biosensors and molecular switches. J Am Chem Soc. 2010. https://doi.org/10.1021/ja9076777.

45. Zhou Z, Xiao L, Xiang Y, Zhou J, Tong A. A general approach for rational design of fluorescent DNA aptazyme sensors based on target-induced unfolding of DNA hairpins. Anal Chim Acta. 2015. https://doi.org/10.1016/j.aca.2015.06.036.

46. Li J, Wang S, Jiang B, Xiang Y, Yuan R. Target-induced structure switching of aptamers facilitates strand displacement for DNAzyme recycling amplification detection of thrombin in human serum. Analyst. 2019. https://doi.org/10.1039/c9an00030e.

47. Chen J, Zuehlke A, Deng B, Peng H, Hou X, Zhang H. A Targettriggered DNAzyme motor enabling homogeneous, amplified detection of proteins. Anal Chem. 2017. https://doi.org/10.1021/acs. analchem.7b03529.

48. Jie G, Tan L, Zhao Y, Wang X. A novel silver nanocluster in situ synthesized as versatile probe for electrochemiluminescence and electrochemical detection of thrombin by multiple signal amplification strategy. Biosens Bioelectron. 2017. https://doi.org/10.1016/j. bios.2017.03.015.

49. Liu Y, Shen T, Li J, Gong H, Chen C, Chen X, et al. Ratiometric fluorescence sensor for the MicroRNA determination by catalyzed hairpin assembly. ACS Sensors. 2017. https://doi.org/10.1021/ acssensors.7b00313.

50. Wang H, Li C, Liu X, Zhou X, Wang F. Construction of an enzyme-free concatenated DNA circuit for signal amplification and intracellular imaging. Chem Sci. 2018. https://doi.org/10. 1039/c8sc01981a.

51. Li C, Li H, Ge J, Jie G. Versatile fluorescence detection of microRNA based on novel DNA hydrogel-amplified signal probes coupled with DNA walker amplification. Chem Commun. 2019. https://doi.org/10.1039/c9cc00565j.

Publisher's note Springer Nature remains neutral with regard to jurisdictional claims in published maps and institutional affiliations. 


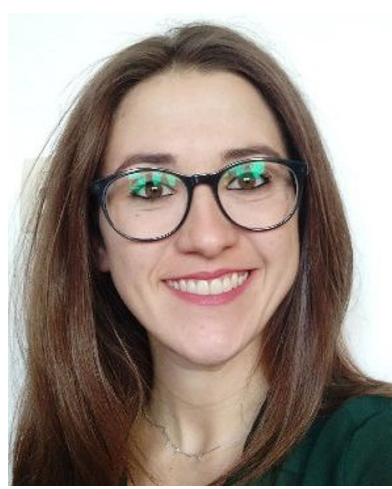

egies in biosensor development.
Aida Montserrat Pagès obtained her Master in Advanced Nanoscience and Nanotechnology (Nanobiotechnology) from Universitat Autònoma de Barcelona (UAB) in 2016. She is now a PhD student in the Biosensors group in the division Mechatronics, Biostatistics and Sensors (MeBioS) of the Biosystems department at $\mathrm{KU}$ Leuven, Belgium. She is currently working on studying the kinetics and reaction mechanism of RNAcleaving DNAzymes for new strat-

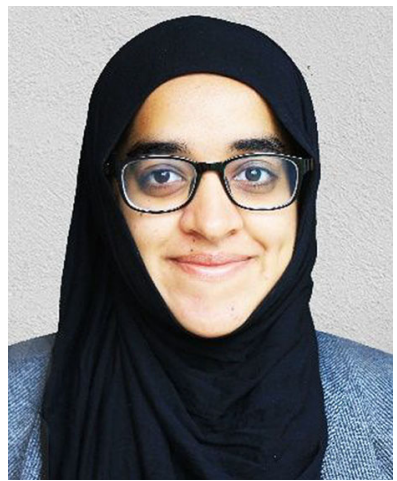

based assays for various in vitro and in vivo applications.
Saba Safdar obtained her Master's in Biomedical Engineering from Arizona State University, USA, in 2016 and her PhD in Bioscience Engineering from KU Leuven, Belgium, in 2020. She is currently a postdoctoral researcher in the Biosensors group in the division Mechatronics, Biostatistics and Sensors (MeBioS) of the Biosystems department at $\mathrm{KU}$ Leuven, Belgium. Her current work focusses on the development of innovative CRISPR-

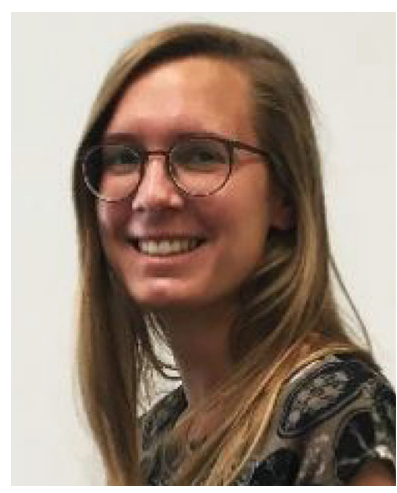

Karen Ven received her Bachelor and Master degrees in Bioscience Engineering from KU Leuven in 2013 and 2015, respectively. In 2020, she received a $\mathrm{PhD}$ degree in Bioscience Engineering from KU Leuven for her work on novel concepts for digital bioassays, in the Biosensors group in the division Mechatronics, Biostatistics and Sensors (MeBioS) of the Biosystems department. She focused on novel fabrication strategies for the platform, as well as NAzyme-based approaches for signal generation and amplification. Currently, she is working in the same group on microfluidic solutions for single-cell analysis and isolation.

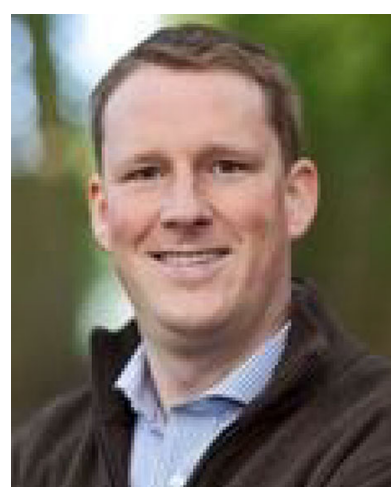

Jeroen Lammertyn is Full Professor in Bionanotechnology at the KU Leuven. He founded the Biosensors group in 2005. The group closely follows the emerging field of food and medical diagnostics and is active in bio-assay development, DNAnanotechnology, optical biosensors, and microfluidics. He is (co-)author of $>300$ peerreviewed research papers, conference papers, and book chapters. $\mathrm{He}$ acts as reviewer for many international peer-reviewed journals, is co-inventor of 12 patent applications, and founder of the spin-off company FOx Biosystems. He is also chairman of the DIATECH 2014 and 2020 International Conferences on Novel technologies for in vitro Diagnostics in Leuven.

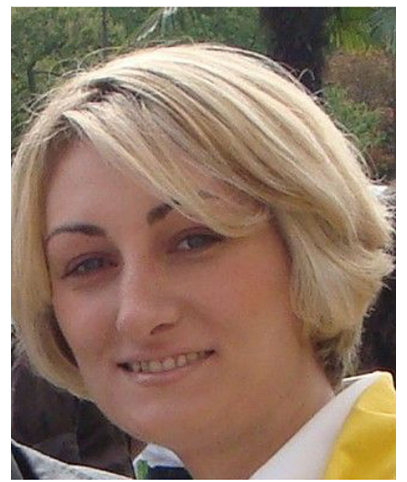

Dragana Spasic received her $\mathrm{MSc}$ and $\mathrm{PhD}$ degrees in Medical Sciences from KU Leuven in 2004 and 2009, respectively. After working as a postdoctoral researcher at the Faculty of Medicine and Bioscience Engineering (KU Leuven), since 2015 she has held a position of Research Manager in the Biosensors group (MeBioS division, KU Leuven). She is (co-)author of $>100$ peer-reviewed research papers, conference papers, and book chapters, and she is involved in research and projects related to development of bioassays and their implementation on various life science research tools and diagnostics platforms. 